\title{
MORTALITY RATE OF AMYOTROPHIC LATERAL SCLEROSIS IN JAPAN: EFFECTS OF MARITAL STATUS AND SOCIAL CLASS, AND GEOGRAPHICAL VARIATION
}

\author{
Yoko IMAIZumi \\ Institute of Population Problems, Ministry of Health \\ and Welfare, Tokyo 100, Japan
}

\begin{abstract}
Summary The ALS death rate in Japan was analyzed using Japanese vital statistics for 1968-1978. The ALS death rate increased gradually year by year for both sexes. The changing patterns of the mortality might be explicable by a constantly improving ascertainment of ALS. There were, however, remarkable differences in the ALS death rates for each sex among the four marital categories. The geographical variations in the ALS death rate were also observed with the highest death rate in Wakayama Prefecture for both sexes. In addition, the difference in the ALS death rate was statistically significant among five occupational categories of the head of the household. The mean age at death from ALS gradually increased year by year for both sexes, though the age was 12 years shorter for males and 17 years shorter for females than that of the general population.

The results suggest the need for extensive epidemiological studies to identify the environmental factors which induce such trends and differences. The factors might be the environmental causes of the disease.
\end{abstract}

\section{INTRODUCTION}

Amyotrophic lateral sclerosis (ALS), a synonym for which is motor neuron disease, is an uncommon disorder in the world except for cluster regions in Guam and the adjacent Mariana Islands and two areas of the Kii Peninsula, Japan (Kurland and Mulder, 1955; Yase, 1973). In most countries, the prevalence rate of ALS is about 4-6 per 100,000 of the population (Goldberg and Kurland, 1962; Kelemen and Bradley, 1983). The rate in Japan also ranged from 2 to 6 per 100,000 of the population except two areas of the Kii Peninsula, where the reported prevalence rates are 74 and 153 per 100,000 of the population (Yase et al., 1968; Yase, 1973).

Espinosa et al. (1962) classified ALS into three types: sporadic or classical ALS, familial ALS, and Guamanian ALS. Sporadic ALS accounts for 90 to $95 \%$ and

Received October 27, 1983/revised version received March 28, 1984 
familial ALS for about 5 to $10 \%$ of all cases of ALS in the United States (Kurland et al., 1968). There is some evidence that genetic factors may play a role in the sporadic forms (Kelemen and Bradley, 1983). In addition, Kurland and Mulder (1955) revealed that the mode of inheritance of familial ALS is autosomal dominant. The clinical features of familial ALS are essentially indistinguishable from the more common sporadic form (Kelemen and Bradley, 1983).

The age-adjusted death rates of ALS in the United States were $0.3-1.0$ per 100,000 of the population for 1959-1961 (Kurland et al., 1973). In Japan, the age-adjusted female death rate from motor neuron disease and muscular atrophies were $0.43-0.58$ for 1952-1971 and were noted to rise after 1952 and to fall rapidly since about 1960 (Kondo and Tsubaki, 1977).

The present study deals with the secular changes and the geographical and seasonal variations in the overall ALS death rate in Japan. It also deals with the effects of marital status and occupation of the head of the household on the ALS death rate.

\section{MATERIALS AND METHODS}

Data consisting of 3,437 deaths with amyotrophic lateral sclerosis (ALS) reported for 1968-1978 inclusive have been obtained from the death certificate records kept at the Ministry of Health and Welfare, Japan. The certificate includes information on the occupation of the head of the household, nationality, sex, place of residence, dates of birth and death, and cause of death. Data on the general population were taken from the annual volumes of the "Vital Statistics of Japan for the Years 19681978" (Health and Welfare Statistics and Information Department, Ministry of Health and Welfare, Japan), which cover the entire population of Japan.

In computing the ALS death rate, the number of postnatal deaths from ALS in each sex were divided by the population size of each sex during the same period. On the other hand, in computing the regional ALS death rate, only the adult population (over 19 years of age) in each prefecture was used as the denominator, where the population size used was the average of that of the two years, 1970 and 1975 .

\section{RESULTS}

Secular change in the ALS mortality rate

Figure 1 shows secular changes in the ALS death rates for each sex. The ALS death rate increased year by year for both sexes. The total number of male deaths from ALS was 142 in 1968 and 266 in 1978. The corresponding death rates per 100,000 of the population were 0.285 and 0.472 , respectively. Therefore, the latter is 1.7 times as high as the former. Similarly, the total number of female deaths from ALS was 73 in 1968 and 177 in 1978. The corresponding death rates per 100,000 of the population were 0.142 and 0.304 , respectively, in which the latter is 2.1 times as 


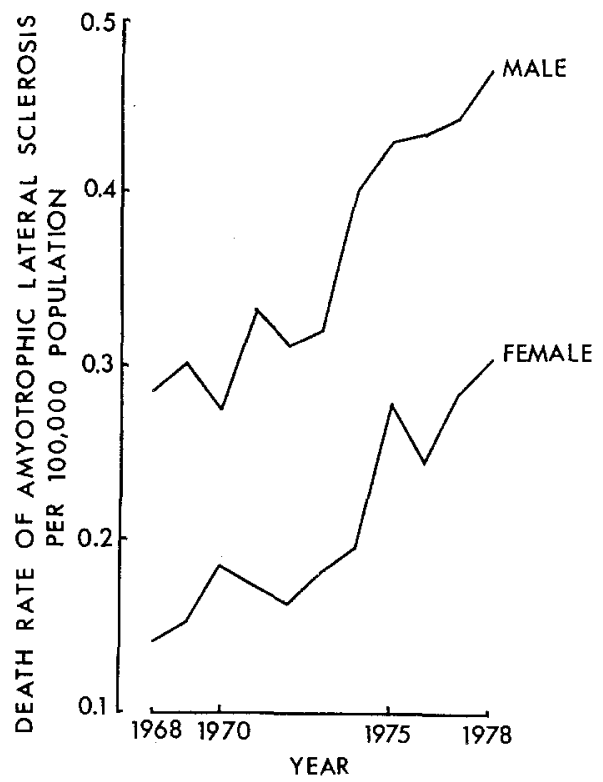

Fig. 1. Secular change of death rate of amyotrophic lateral sclerosis by sex during 19681978.

high as the former. The linear regression coefficients of the ALS death rate on the year (per 100,000 years) are $0.0206( \pm 0.0024)$ for males and $0.0159( \pm 0.0022)$ for females. These values were significant at the $1 \%$ level.

The sex ratio of death due to ALS (male-to-female ratio) was 1.95 in 1968 and 1.50 in 1978 . Therefore, the sex ratio gradually decreased with the year, but still a male preponderance was noted.

\section{Age-specific mortality rates of $A L S$}

Figure 2 shows the age-specific ALS death rate by sex during the period from 1968 to 1978. In both sexes, the ALS death rate per 100,000 of the population slowly increased up to the 35-39 age group and rapidly increased thereafter up to the 65-69 age group and decreased thereafter. The age-specific death rate is always statistically significantly higher in males than in females except under 35 , where the death rates are similar for both sexes.

\section{Material status}

Table 1 shows age-specific ALS death rates by sex and marital status for 19691978. To compute the age-specific ALS death rate by sex and marital status during the period, the size of the population more than 14 years of age in 1975 was used as the denominator. The ALS death rate in each age category was higher in the single than in the married group for both sexes, except for males over 75 years of age. 


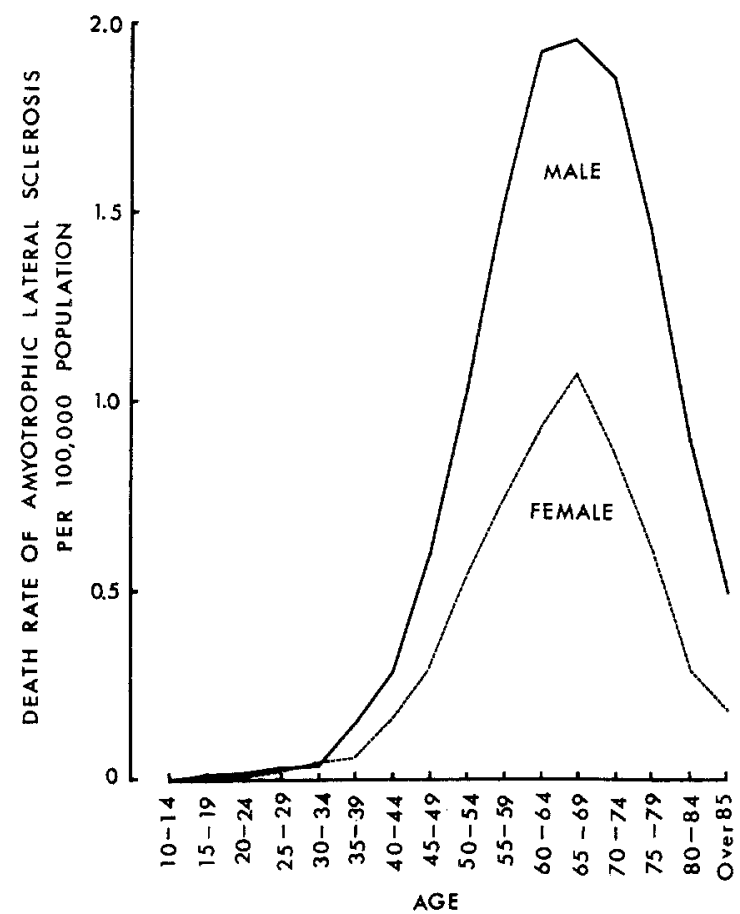

Fig. 2. Age-specific death rate of amyotrophic lateral sclerosis by sex during 1968-1978.

For most age categories, the ALS death rate was lower in the married group than in the widowed and divorced groups for both sexes.

Table 2 illustrates average annual age-adjusted ALS death rates by age, sex and marital status which were computed using age-specific ALS death rates in each marital status for 1969-1978 (Table 1) and for the size of the population more than 14 years of age in 1975. The lowest age-adjusted death rate per 100,000 of the population was seen in the married group for both males (0.469) and females $(0.270)$. On the other hand, the highest death rate for males was seen in the widowed group $(0.947)$, followed in order by the single group (0.811) and the divorced group $(0.577)$, whereas the highest death rate for females was seen in the single group (0.473), followed in order by the divorced group (0.423) and the widowed group (0.348). For males, the age-adjusted death rate in the widowed group was two times as high as the rate in the married group. For females, the age-adjusted death rate in the single group was 1.8 times as high as the rate in the married group.

\section{Geographical variation}

Figure 3 shows the ALS death rate by sex and prefecture during the period from 1968 to 1978. All prefectures but four for males and five for females had ALS death rates in the range from 0.35 to 0.85 and from 0.15 to 0.50 , respectively, 
Table 1. Deaths and average annual death rates for amyotrophic lateral sclerosis (ALS) by age, sex and marital status, 1969-1978.

\begin{tabular}{|c|c|c|c|c|c|c|c|c|}
\hline \multirow{2}{*}{ Age } & \multicolumn{4}{|c|}{ Male } & \multicolumn{4}{|c|}{ Female } \\
\hline & Single & Married & Widowed & Divorced & Single & Married & Widowed & Divorced \\
\hline & \multicolumn{8}{|c|}{ Number of deaths with ALS } \\
\hline Total & 105 & 1,710 & 161 & 31 & 80 & 705 & 375 & 49 \\
\hline Under 15 & 2 & - & - & - & 3 & - & - & 一 \\
\hline $15-24$ & 18 & - & - & - & 8 & - & - & - \\
\hline $25-34$ & 16 & 12 & 1 & 2 & 15 & 17 & 1 & 2 \\
\hline $35-44$ & 28 & 142 & 1 & 5 & 7 & 83 & 4 & 3 \\
\hline $45-54$ & 22 & 410 & 15 & 7 & 21 & 201 & 31 & 11 \\
\hline $55-64$ & 13 & 638 & 31 & 10 & 14 & 250 & 119 & 23 \\
\hline $65-74$ & 5 & 413 & 81 & 6 & 9 & 136 & 170 & 6 \\
\hline \multirow[t]{2}{*}{ Over 75} & 1 & 95 & 32 & 1 & 3 & 18 & 50 & 4 \\
\hline & \multicolumn{8}{|c|}{ Average annual death rate of ALS per 100,000 population } \\
\hline Total & $0.0879^{\mathrm{a}}$ & 0.6171 & 1.5286 & 0.7989 & $0.0853^{\mathrm{a}}$ & 0.2540 & 0.6796 & 0.5415 \\
\hline $15-24$ & 0.0224 & 0 & 0 & 0 & 0.0115 & 0 & 0 & 0 \\
\hline $25-34$ & 0.0488 & 0.0179 & 1. 1099 & 0.2987 & 0.1016 & 0.0204 & 0.2340 & 0.1387 \\
\hline $35-44$ & 0.6888 & 0.1825 & 0.2923 & 0.4406 & 0.1638 & 0.1114 & 0.1999 & 0.1304 \\
\hline $45-54$ & 1.6105 & 0.6887 & 1.7926 & 0.7115 & 0.7008 & 0.3551 & 0.4862 & 0.4076 \\
\hline $55-64$ & 2.6745 & 1.7121 & 1.7857 & 1.6955 & 1. 2127 & 0.7765 & 0.8180 & 1.4683 \\
\hline $65-74$ & 1.9241 & 1.8021 & 2. 2090 & 1.7705 & 1.5855 & 0.9673 & 0.9575 & 0.9132 \\
\hline Over 75 & 0.7726 & 1.3395 & 0.8316 & 0.8767 & 1.2151 & 0.6684 & 0.3564 & 1.6719 \\
\hline
\end{tabular}

a Including number of deaths with ALS under 15 years old.

Table 2. Average annual age-adjusted death rates for ALS, by age, sex and marital status, 1969-1978.

\begin{tabular}{llcc}
\multirow{2}{*}{$\begin{array}{l}\text { Marital status } \\
\end{array}$} & \multicolumn{3}{c}{$\begin{array}{c}\text { Age-adjusted death rate per 100,000 of the population } \\
\text { more than 14 years of age }\end{array}$} \\
\cline { 2 - 4 } & Male & Female & Male/Female \\
\hline Single & 0.8111 & 0.4734 & 1.71 \\
Married & 0.4690 & 0.2700 & 1.74 \\
Widowed & 0.9470 & 0.3482 & 2.72 \\
Divorced & 0.5772 & 0.4232 & 1.36 \\
\hline
\end{tabular}


DEATH RATE OF AMYOTRPHIC LATERAL SCLEROSIS PER 100,000 POPULATION

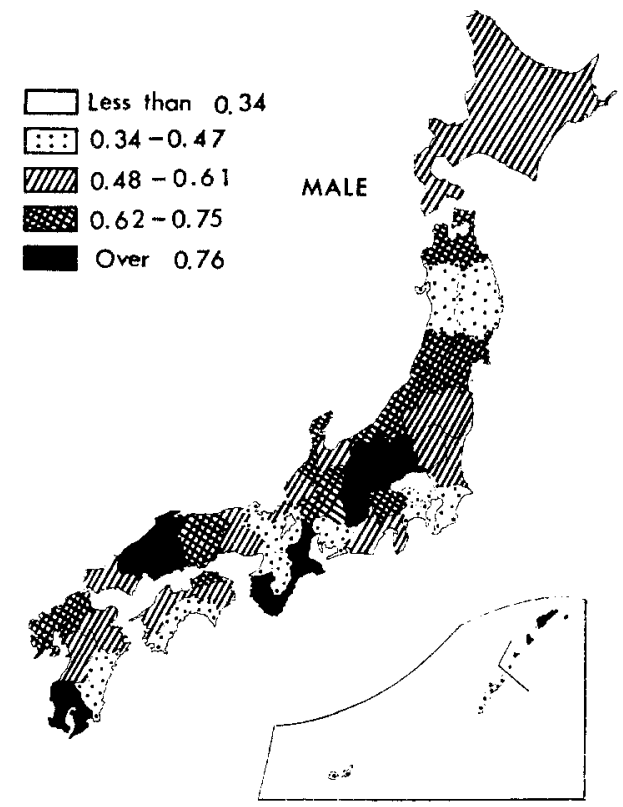

DEATH RATE OF AMYOTROPHIC LATERAL SCLEROSIS PER 100,000 POPULATION

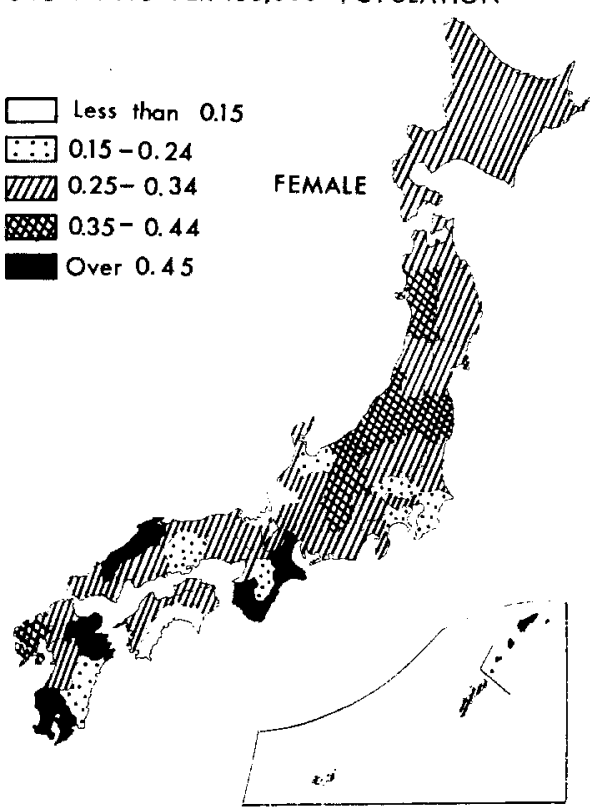

Fig. 3. Geographical distribution of death rate of amyotrophic lateral sclerosis by sex during 1968-1978.

per 100,000 of the population. The overall ALS death rate per 100,000 of the population in Japan was 0.552 for males and 0.307 for females. The highest ALS death rate was seen in Wakayama prefecture (1.526 for males and 0.678 for females), which is located in the Kii Peninsula. Therefore, the ALS death rate in Wakayama prefecture is 2.8 times for males and 2.2 times for females as high as the overall ALS death rate in Japan. The second highest male ALS death rate was seen in Mie (0.937), followed in order by Nagano (0.883) and Shimane prefectures (0.840), whereas the second highest female ALS death rate was seen in Shimane (0.655) followed in order by Oita (0.644) and Mie prefectures (0.475). On the other hand, the lowest ALS death rate was seen in Saitama (0.337) for males and in Fukui (0.132) for females. The second lowest male ALS death rate was seen in Kochi $(0.382)$ followed in order by Shiga (0.387) and Okinawa prefectures $(0.400)$, while the second lowest female death rate was seen in Kochi $(0.147)$ followed in order by Nara $(0.177)$ and Saitama prefectures (0.191). The high ALS death rate for both sexes was seen in Wakayama, Mie, Shimane and Kagoshima prefectures, whereas the low ALS death rate for both sexes was seen in Saitama and Kochi prefectures.

Table 3 shows age-adjusted ALS death rates by sex, urban and rural areas for 1969-1978. The death rate was higher in rural areas than urban areas for males, but in the reverse order for females. However, crude ALS death rate was higher in rural areas than urban areas for both sexes. 
Table 3. Death rates and age-adjusted death rates for amyotrophic lateral sclerosis (ALS), by sex, urban and rural areas, 1969-1978.

\begin{tabular}{clcc}
\hline Sex & & Urban areas & Rural areas \\
\hline \multirow{2}{*}{ Male } & Number of ALS & 1,369 & 631 \\
& Death rate of ALS per 100,000 & 0.3466 & 0.4672 \\
& Age-adjusted death rate of ALS per 100,000 & 0.3246 & 0.3419 \\
Female & Number of ALS & 255 & 354 \\
& Death rate of ALS per 100,000 & 0.2116 & 0.2456 \\
& Age-adjusted death rate of ALS per 100,000 & 0.1851 & 0.1781 \\
\hline
\end{tabular}

\section{Seasonal variation}

Figure 4 shows the death rates for the ALS and all causes by month of death during the period from 1969 to 1978 . The highest ALS death rate per 100,000 of the population was seen in January $(0.35)$, followed in order by November $(0.33)$ and August (0.32), whereas the highest death rate for all causes was also seen in January (783.37), followed in order by February (760.03) and March (722.27). The lowest ALS death rate was seen in June and May (0.25), followed in order by October (0.28) and April (0.29), whereas the lowest death rate for all causes was seen in September (557.14), followed in order by June (575.86) and August (576.20). Therefore, seasonal variations in the ALS death rates and all causes indicated a similar tendency except in July and August in which the greatest discrepancy in the death rate was observed between ALS and all causes.

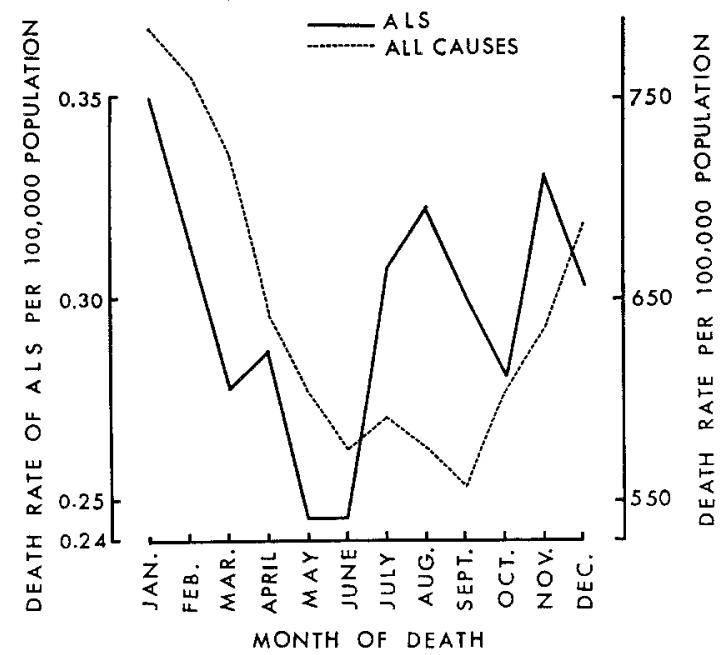

Fig. 4. Seasonal variations in death rates for amyotrophic lateral sclerosis (ALS) and all causes during 1968-1978. 
Table 4. Observed and expected numbers of deaths from amyotrophic lateral sclerosis (ALS) by month, 1969-1978.

\begin{tabular}{lcccc}
\hline Month of death & \multicolumn{2}{c}{ Numbers of deaths } & $\chi^{2}$ & $\begin{array}{c}\text { Death rate of ALS } \\
\text { per 100,000 of the } \\
\text { population }\end{array}$ \\
\cline { 2 - 5 } & Obs. & Exp. & & 0.3507 \\
\hline January & 321 & 272 & $8.83^{\mathrm{a}}$ & 0.3129 \\
February & 259 & 246 & 0.69 & 0.2780 \\
March & 255 & 273 & 1.19 & 0.2870 \\
April & 255 & 264 & 0.31 & 0.2470 \\
May & 227 & 273 & $7.75^{\mathrm{a}}$ & 0.2460 \\
June & 219 & 265 & $7.98^{\mathrm{a}}$ & 0.3073 \\
July & 283 & 274 & 0.30 & 0.3233 \\
August & 298 & 274 & 2.10 & 0.3012 \\
September & 269 & 266 & 0.03 & 0.2804 \\
October & 259 & 275 & 0.93 & 0.3308 \\
November & 296 & 266 & 3.38 & 0.3036 \\
December & 281 & 275 & 0.13 & 0.2973 \\
\hline Total & 3,222 & & $33.62^{\mathrm{a}}$ & \\
\hline
\end{tabular}

Significant at the $1 \%$ level.

Table 4 shows observed and expected numbers of deaths from ALS by month for 1969-1978. The difference between observed and expected numbers of deaths due to ALS was significant at the $1 \%$ level in January, May and June. The departure from homogeneity during the 12 months was significant at the $1 \%$ level.

\section{Occupation}

Table 5 shows the number of deaths from ALS by occupation of the head of the household. These occupations were classified into six categories according to the classification in the certificate records: I (agriculture only), II (agriculture with other work), III (self employed), IV (white collar), V (blue collar) and VI (other). Expected numbers of deaths in Table 5 were calculated based on the total numbers of deaths from ALS for 1969-1978 and the rate of each occupation in total numbers of occupations of the head of the household. The number of deaths from ALS was higher in the observed than in the expected values for categories III, IV, and VI, whereas the opposite tendency was seen in categories I and II. The difference between the observed and the expected numbers of deaths from ALS was statistically significant in the five categories.

\section{Mean age at death}

Figure 5 shows the secular change in the mean age at death from ALS in each sex during the period from 1968 to 1978. The mean ages at death from ALS were 
Table 5. Observed and expected numbers of deaths from amyotrophic lateral sclerosis (ALS) by occupation of the head of household, 1969-1978.

\begin{tabular}{|c|c|c|c|c|}
\hline \multicolumn{2}{|c|}{ Occupation } & \multicolumn{2}{|c|}{ Number of ALS } & $\chi^{2}$ \\
\hline \multirow[t]{2}{*}{ I } & Agriculture only & Obs. & 405 & \multirow{2}{*}{$40.54^{\mathrm{a}}$} \\
\hline & & Exp. & 555 & \\
\hline \multirow[t]{2}{*}{ II } & Agriculture with other works & Obs. & 353 & \multirow{2}{*}{$11.58^{\mathrm{a}}$} \\
\hline & & Exp. & 423 & \\
\hline \multirow[t]{2}{*}{ III } & Self employed & Obs. & 487 & \multirow{2}{*}{$9.68^{\mathrm{a}}$} \\
\hline & & Exp. & 423 & \\
\hline & Employee (white collar) & Obs. & 563 & \multirow{2}{*}{$17.54^{\mathrm{a}}$} \\
\hline & & Exp. & 472 & \\
\hline & Employee (blue collar) & Obs. & 522 & \multirow{2}{*}{0.01} \\
\hline & & Exp. & 520 & \\
\hline & Other & Obs. & 888 & \multirow{2}{*}{$4.81^{\mathrm{b}}$} \\
\hline & & Exp. & 825 & \\
\hline
\end{tabular}

${ }^{a}$ Significant at the $1 \%$ level. $\chi_{5}{ }^{2}=84.16$. b Significant at the $5 \%$ level.

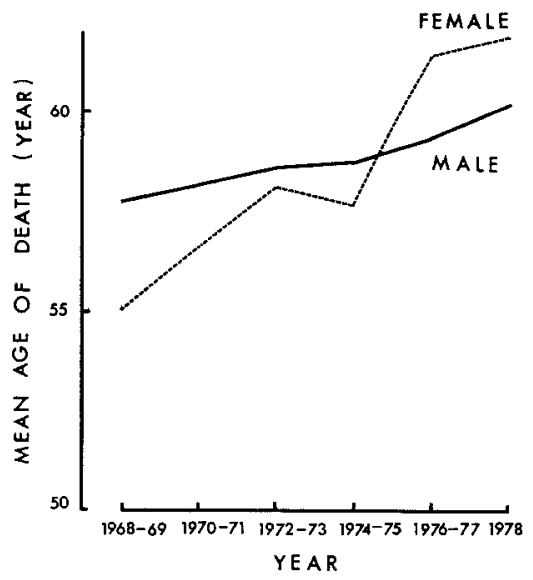

Fig. 5. Trend of mean age at death of amyotrophic lateral sclerosis by sex during 19681978.

$57.5( \pm 12.8)$ years for males and $56.4( \pm 11.5)$ years for females in 1968 and the corresponding ages in 1978 were $60.2( \pm 11.8)$ years for males and $61.9( \pm 10.5)$ years for females. The mean age at death for both sexes gradually increased with time. The mean age at death from ALS was higher in males than in females until 1975, and reversed thereafter. Accordingly, life expectancy for the last decade was longer in females ( 5.5 years) than in males ( 2.7 years). 


\section{DISCUSSION}

According to Kurtzke (1982), the ALS death rate increased year by year in the United States during 1949-1976. The same tendency was also observed in the present study (Fig. 1). The sex ratio of the death from ALS was 1.76 in the United States during the period from 1959 to 1961 (Kurland et al., 1973), whereas the sex ratio was $1.68(2,153 / 1,284)$ in Japan during the period from 1968 to 1978 and the ratio decreased with the year. The reason for the decline in the sex ratio is not clear. Increased ALS death rates for both sexes might be explicable by a constantly improving ascertainment of ALS and by some environmental factors.

According to Kurland et al. (1968), there were no remarkable differences in the ALS death rates for each sex among the four marital categories in the United States during the period from 1959 to 1961. In the present study, the age-adjusted ALS death rate was the lowest in the married group for both sexes. The ALS death rate was two times higher in the widowed than in the married group for males, whereas the death rate was 1.8 times higher in the single group than in the married group for females. On the other hand, the sex ratio of the death from ALS was 2.72 for the widowed and 1.36 for the divorced groups (Table 2). Since the overall sex ratio of the death from ALS was 1.68, a higher risk for ALS in males than in females was especially seen in the widowed group, but the risk in the divorced group was nearly similar for both sexes. Remarkable differences in the ALS death rates among the four marital categories in Japan might be related to some environmental factor or factors such as nutrition.

The highest prevalence rates of ALS in Japan have been observed in two areas of the Kii Peninsula: Kozagawa and Hobara areas. The former area is in Wakayama prefecture and the latter in Mie prefecture. Similarly, the highest ALS death rates were seen in Wakayama and Mie prefectures for both sexes in the present study. According to Kurland et al. (1973), a reasonable duration from clinical onset to death for ALS was around four years. The ALS death rate seems to be parallel with the prevalence rate. Therefore, it is considered that the geographical variations in the ALS death rate also represent those of the prevalence rate in Japan.

The mean age at death from ALS was 61.1 years for both sexes in the United States during the period from 1959 to 1961 (Kurland et al., 1973). In the present study, the mean age at death from ALS gradually increased year by year during the period from 1968 to 1978 , and it was 60.2 years for males and 61.9 years for females in 1978. Therefore, considering the time lag of 17 years, the Japanese patients with ALS still have a short life compared with those in the United States. On the other hand, the Japanese life expectancy in 1968 was 69.1 years for males and 74.3 years for females, and the corresponding value in 1978 was 73.0 and 78.3 years, respectively (Institute of Population Problems, Ministry of Health and Welfare, 1979). In the present study, the mean age at death from ALS in 1968 was 57.5 years for males and 
56.4 years for females. Accordingly, for the last decade, the mean age at death from ALS was 12 years shorter for males, and 17 years shorter for females, compared with overall Japanese life expectancy.

As to the causes of ALS, Kelemen and Bradley (1983) suggested an underlying genetic predisposition which can be acted on by a number of precipitating factors. Viruses, heavy metals and so forth have been suggested as possible etiological factors (Yase, 1977; Kelemen and Bradley, 1983). In case-control studies of motor neuron disease in Japan, a positive association with mechanical injuries was observed but no association was observed with smoking, drinking, residence, home space, drinking water, parental consanguinity, the parental age, birth order, sib size, measles, polio, mumps, and tuberculosis (Kondo and Tsubaki, 1981; Kondo and Fujiki, 1984). The results obtained in this study shows a rising trend of death from ALS and differences in the ALS death rate among four marital categories, among five occupational categories of the head of the household, and among different prefectures. These results suggest the need for extensive epidemiological studies to identify the environmental factors which induce such trends and differences. The factors might be the environmental causes of the diseases.

\section{REFERENCES}

Espinosa, R.E., Okihiro, M.M., Mulder, D.W., and Sayre, G.P. 1962. Hereditary amyotrophic lateral sclerosis. Neurology 12: 1-7.

Goldberg, I.D. and Kurland, L.T. 1962. Mortality in 33 countries from diseases of the nervous system. World Neurol. 3: 444-465.

Kelemen, J. and Bradley, W.G. 1983. Motor neuron diseases. In Principles and Practice of Medical Genetics, Emery, A.H. and Rimoin, D.L., eds., Vol. 1, Churchill Livingstone, Edinburgh, London, Melbourne and New York, pp. 451-461.

Kondo, K. and Fujiki, K. 1984. Effects of parental age and birth order in motor neuron disease. Jpn. J. Human Genet. 29: 45-50.

Kondo, K. and Tsubaki, T. 1977. Changing mortality patterns of motor neuron diseases in Japan. J. Neurol. Sci. 32: 411-424.

Kondo, K. and Tsubaki, T. 1981. Case-control studies of motor neuron disease, association with mechanical injuries. Arch. Neurol. 38: 220-226.

Kurland, L.T. and Mulder, D.W. 1955 . Epidemiologic investigations of amyotrophic lateral sclerosis. 2. Familial aggregations of dominant inheritance. Neurology 5: 182-196, 249-268.

Kurland, L.T., Choi, N.W., and Sayre, G.P. 1968. Implications of incidence and geographical patterns on the classification of amyotrophic lateral sclerosis. In Motor Neuron Diseases: Research on Amyotrophic Lateral Sclerosis and Related Disorders, Norris, F.H. and Kurland, L.T., eds., Grune \& Stratton, New York, pp. 28-50.

Kurland, L.T., Kurtzke, J.F., Goldberg, I.D., and Choi, N.W. 1973. Amyotrophic lateral sclerosis and other motor neuron diseases. In Epidemiologic and Sense Organ Disorders, Kurland, L.T., Kurtzke, J.F., and Goldberg, I.G., eds., Harvard, Cambridge, Mass., pp. 108-127.

Kurtzke, J.F. 1982. Epidemiology of amyotrophic lateral sclerosis. Adv. Neurol. 36: 281-302.

Yase, Y. 1973. Epidemiological study of amyotrophic lateral sclerosis in the Kii Peninsula, Japan. Adv. Neurol. Sci. (Tokyo) (in Japanese) 17: 30-33.

Yase, Y. 1977. ALS in the Kii Peninsula, one possible etiological hypothesis. In Amyotrophic Lateral Sclerosis, Tsubaki, T., ed., University of Tokyo Press, Tokyo, pp. 307-317.

Yase, Y., Matsumoto, N., Yoshimasu, F., Handa, Y., and Kumamoto, T. 1968. Motor neuron disease in the Kii Peninsula, Japan. Proc. Aust. Assoc. Neurol. 5: 335-339. 